\title{
AÇÃO EMPREENDEDORA NO SETOR PÚBLICO: A CRIAÇÃO DO SETOR DE "PÓS- COMPRA" EM UMA UNIVERSIDADE PÚBLICA DO SUL DE MINAS GERAIS
}

Gilson Lacerda ${ }^{1}$

Daniela Andrade $^{1}$

${ }^{1}$ Universidade Federal de Lavras 


\title{
AÇÃO EMPREENDEDORA NO SETOR PÚBLICO: A CRIAÇÃO DO SETOR DE "PÓS-COMPRA" EM UMA UNIVERSIDADE PÚBLICA DO SUL DE MINAS GERAIS
}

\begin{abstract}
Resumo: O objetivo deste artigo é descrever o processo de criação e implementação do setor de "Pós-compra" em uma Universidade pública do sul de Minas Gerais e analisar se essa ação pode ser considerada empreendedora. Para isso, adotou-se uma abordagem qualitativa e descritiva, apoiada na realização de um estudo de caso observacional. As informações foram obtidas através de três técnicas (observação participante, entrevista semiestruturada e pesquisa documental) e analisadas pela técnica da análise temática, a partir do esquema teórico proposto. O processo de criação do setor de "Pós-compra" iniciou-se no final de 2015 em um contexto marcado pela falta de eficiência nas práticas de acompanhamento e controle das obrigações contratuais e legais por parte dos licitantes e contratadas. O setor proporcionou diferentes resultados sociais que se manifestaram através da geração de benefícios qualitativos e quantitativos. Por fim, tem-se que essa ação pode ser considerada empreendedora.
\end{abstract}

Palavras-chave: Ação empreendedora. Empreendedorismo público. Ação empreendedora no setor público. Compras públicas.

\section{$1 \quad$ Introdução}

Seja no setor privado ou público, as abordagens do empreendedorismo normalmente dão mais ênfase ao indivíduo do que à ação empreendedora propriamente dita. No entanto, essa forma individualista de investigar o empreendedorismo passou a ser questionada por alguns autores, como Paiva Júnior (2004), Klein (2008), Gomes (2010), Gomes, Lima e Cappelle (2013), Watson (2013), Spedale e Watson (2014), Borges (2018) e Nascimento (2018), os quais propõem estudar o fenômeno por uma perspectiva mais abrangente, qual seja, a da ação empreendedora.

No entendimento de Zen e Fracasso (2008) e Lima (2010), nas organizações privadas, a ação empreendedora pode ser compreendida como uma ação coletiva que, a partir da criação de novos bens e serviços, visa proporcionar valor econômico (BOSZCZOWSKI; TEIXEIRA, 2012). Já no setor público, embora a ação coletiva também seja uma característica das ações empreendedoras (SOUSA; PAIVA JÚNIOR; LIRA, 2010; SOUSA 2010), estas são voltadas para a geração de benefícios sociais (XAVIER FILHO et al., 2014). Nas Universidades públicas, por exemplo, Marques (2016) explica que as ações empreendedoras são induzidas pelas iniciativas dos dirigentes, porém, ressalta que, embora a atuação do gestor seja relevante, o que se observa, na prática, é uma ação coletiva que busca diversos objetivos.

Ainda no contexto das Instituições Federais de Ensino Superior (IFES), Guimarães (2014) acrescenta a ação empreendedora perpassa por um movimento inovador e remete ao desafio de encontrar alternativas que sejam eficientes e atendam aos anseios da comunidade acadêmica. Biazzi, Muscat e Biazzi (2011) afirmam que, ao longo das últimas décadas, as IFES vêm buscando melhores formas de atuar por meio da criação de novos processos e práticas de gestão para atender ao interesse dos seus stakeholders, tendência que pode ser observada na área de compras públicas. Assis (2015) comenta que os governos têm criado 
processos e métodos de trabalho mais ágeis, flexíveis e eficientes para realizar suas aquisições e contratações, sem, contudo, deixar de observar as obrigações legais.

Essa preocupação e esforço dos órgãos públicos, especialmente das IFES, em ter uma gestão mais adequada dos recursos e de criar novas práticas e procedimentos internos, é um tema abordado na pesquisa de Pinheiro (2017), na qual destaca-se a importância do trabalho de um setor de "Pós-compra" no sentido de exercer a função de monitorar e controlar o cumprimento das obrigações contratuais e legais, por parte dos licitantes e contratadas, bem como apurar eventual descumprimento de tais obrigações. Abreu (2015) explica que, nos casos de inadimplemento, a Administração Pública deve instaurar Processo Administrativo Sancionatório, a fim de apurar a infração cometida pela empresa licitante ou contratada e aplicar, quando devido, as sanções previstas na legislação e em contrato.

Ao comparar a estrutura de aplicação de sanções administrativas de quatro IFES situadas em Minas Gerais (MG), Pinheiro (2017) explica que, na prática, as penalidades retrocitadas não são aplicadas de maneira eficiente pelas IFES. Não obstante, no final do ano de 2015, uma Universidade pública do sul de MG (UPSMG), a partir de uma ideia oriunda de servidores lotados em diferentes setores administrativos da instituição, deu início ao processo de criação e implementação de um setor de "Pós-compra" para atuar, especialmente, no acompanhamento e controle do cumprimento das obrigações contratuais e legais pelos fornecedores e na apuração de eventuais infrações administrativas.

Informações disponibilizadas no Painel de Compras do Governo Federal mostram a participação da UPSMG no total de compras efetuadas pelo Ministério da Educação (MEC) no ano de 2018. Neste mesmo ano, o MEC realizou mais de 58 mil processos de compras, perfazendo um valor de aproximadamente 11,4 bilhões de reais. Do montante desse valor, cerca de 62,4 milhões foram destinados aos mais de 170 processos de compras realizados pela UPSMG (BRASIL, 2019).

Em acréscimo, um estudo realizado pelo Tribunal de Contas da União (TCU) em 2018 para verificar a vulnerabilidade dos órgãos públicos federais quanto a fraudes e corrupção, constatou que a UPSMG teve o menor índice de fragilidade no controle de fraudes e corrupção dentre as dezenove IFES mineiras analisadas, ou seja, é a IFES que possui os mecanismos de prevenção mais fortes contra fraudes e corrupção no Estado de MG. Já em nível nacional, essa IFES ficou com o segundo melhor resultado (BRASIL, 2018).

Em vista da ação dessa Universidade mineira em criar o setor de "Pós-compra" e da sua importância e destaque no cenário nacional, especialmente em matéria de gestão, surge a seguinte indagação: a criação do setor de "Pós-compra" em uma UPSMG pode ser compreendida como uma ação empreendedora? Para responder ao problema apresentado, o objetivo deste artigo é descrever o processo de criação e implementação do setor de "Póscompra" em uma UPSMG e analisar se essa ação pode ser considerada empreendedora. Os objetivos específicos são: $i$ ) propor um esquema teórico para analisar a ocorrência da ação empreendedora no setor público; e ii) analisar a criação do setor a partir do referido esquema.

Uma das contribuições deste trabalho consiste em deslocar o foco dos estudos que destacam o indivíduo empreendedor, para a ação empreendedora propriamente dita. $\mathrm{O}$ artigo também se justifica, na medida em que contribui para o campo de estudos sobre empreendedorismo público. O estudo pretende, ainda, explorar o tema do "Pós-compra" nas organizações públicas que, na visão de Pinheiro (2017), é pouco explorado na literatura. 


\section{Ação empreendedora no setor público}

Nascimento (2018) entende que as ações empreendedoras públicas surgem do diálogo, compartilhamento de informações e conhecimentos entre diferentes pessoas, bem como do trabalho coletivo de atores na criação ou melhoria de um empreendimento, produção de novos bens e serviços ou, ainda, na resolução de tensões e conflitos que culmina em um processo inovador para atender demandas públicas. Para Borges (2018), a ação empreendedora pública pode ser desenvolvida em diversas áreas e surgir de ações individuais ou coletivas, as quais podem partir de diferentes níveis hierárquicos da organização ou da própria sociedade civil.

Silva, Valadares e Andrade (2016) explicam que a ação empreendedora no setor público pode ocorrer por meio da formulação e implementação de políticas públicas que visam o atendimento de questões relacionadas à emancipação social, política e econômica.

Nascimento (2018) explica o processo de emergência da ação empreendedora pública a partir dos conceitos de orientação de vida, lógicas e tensões institucionais. A orientação de vida é o processo pelo qual o indivíduo atribui significados à sua circunstância pessoal e social (WATSON, 2013; SPEDALE; WATSON, 2014). É, também, um conjunto de padrões biográficos, como a história pessoal, as vivências, os valores éticos e os hábitos positivos (NASCIMENTO, 2018), sendo estes entendidos como a repetição de práticas de sucesso (SPEDALE; WATSON, 2014) que influenciam as ações cotidianas. As lógicas institucionais são os padrões históricos, construídos a partir de práticas materiais, valores e crenças, que conduzem a organização e o comportamento dos seus membros (THORNTON; OCASIO, 1999; SPEDALE; WATSON, 2014). Já as tensões são as circunstâncias pessoais ou sociais que levam as pessoas a agirem de uma forma diferente (WATSON, 2013; SPEDALE; WATSON, 2014), isto é, são situações que, por causarem algum desconforto, devem ser modificadas. As tensões institucionais são situações em que as rotinas estabelecidas são colocadas em "xeque", ou seja, é quando as pessoas identificam que determinada prática organizacional precisa ser alterada (SPEDALE; WATSON, 2014). Assim, quando considerados em conjunto, os conceitos de lógicas e tensões institucionais retratam o contexto organizacional, pois englobam temas como as práticas, padrões e rotinas organizacionais.

Sousa, Paiva Júnior e Lira (2010) explicam que os valores éticos orientam a boa conduta das pessoas e que a presença desses valores na ação empreendedora pública traz credibilidade e confiança aos demais atores e parceiros envolvidos na ação.

Alguns autores como Groot e Dankbaar (2014) e Silva, Valadares e Andrade (2016) argumentam que a ação empreendedora pública pode ser identificada por meio de resultados positivos gerados no contexto da sociedade na qual foi desenvolvida e implementada.

Na visão de Paiva Júnior (2004) e Sousa, Paiva Júnior e Lira (2010), a ação empreendedora pública envolve o reconhecimento de oportunidades de negócios para criar um novo empreendimento ou melhorar algum já estabelecido. Para estes autores, reconhecer uma oportunidade de negócio no setor público normalmente significa romper com o que está instituído. Klein (2008) explica que a oportunidade pode ser entendida como um construto latente que se manifesta na ação empreendedora pública. Nascimento (2018) complementa que as oportunidades são criadas por meio das ações e interações dos indivíduos.

Welter (2011) argumenta que o contexto pode oferecer oportunidades aos indivíduos, mas também restringir suas ações. Desse modo, tanto o contexto organizacional como o contexto externo à organização, o qual está relacionado às estruturas e processos históricos, 
políticos e legais, as instituições e organizações (BURKE et al., 2009), podem influenciar as ações empreendedoras públicas que, por sua vez, podem impactar tais contextos. Para Sarason, Dean e Dillard (2006), as estruturas sociais também podem limitar e capacitar os empreendedores na descoberta, avaliação e exploração de oportunidades, as quais tomam forma quando o empreendedor as define como tal, ou seja, as oportunidades são retratadas pelos indivíduos como um fenômeno singular. Assim, pode existir uma mesma oportunidade para todos os indivíduos, mas cada um a interpreta de uma forma, isto é, as oportunidades são criadas a partir da interpretação dos sujeitos (SARASON; DEAN; DILLARD, 2006).

Sousa (2010), corroborando com Paiva Júnior (2004) e Sousa, Paiva Júnior e Lira (2010), explica que as ações empreendedoras públicas, por meio de práticas inovadoras, como a formulação e implementação de uma nova política pública (SILVA; VALADARES; ANDRADE, 2016), a criação de novos produtos e serviços ou de um novo empreendimento, a reestruturação de determinado processo, a utilização de métodos de trabalho criativos ou, ainda, a introdução de mudanças administrativas (GOMES; LIMA; CAPPELLE, 2013; NASCIMENTO, 2018), podem romper com arranjos institucionais existentes.

Para Borges e Cappelle (2017), embora as organizações públicas tenham uma estrutura menos flexível em relação às organizações privadas, pela ação empreendedora, não apenas o gestor, mas também outros agentes públicos e a população, podem se tornar verdadeiros indutores de mudanças.

Não obstante, Paiva Júnior (2004), Sousa (2010) e Sousa, Paiva Júnior e Lira (2010), compartilhando da mesma visão, ponderam que as mudanças e os resultados sociais proporcionados pela ação empreendedora pública, dentre eles, a geração de benefícios sociais, satisfação das necessidades do cidadão e atendimento ao interesse público (PAIVA JÚNIOR, 2004; SOUSA, 2010; XAVIER FILHO et al., 2014), não são reflexos de ações individuais, mas de um esforço conjunto, de uma mobilização que é capaz de criar alianças e formas de cooperação com organizações do poder público e setor privado, de modo a ampliar as oportunidades de negócios e promover a transformação social.

Dessa forma, no setor público, as ações empreendedoras revelam um espírito de coletividade que pode favorecer a criação de parcerias. Com isso, torna-se mais fácil a construção de alianças entre os setores público e privado e a sociedade civil (SOUSA; PAIVA JÚNIOR; LIRA, 2010; SOUSA 2010; BORGES, 2018). O espírito de coletividade está atrelado à interação social, que é a interação dos diferentes atores envolvidos na ação empreendedora. Esta interação, por sua vez, pressupõe a comunicação do empreendedor com outros parceiros que fazem parte da sua rede social (GOMES; PAIVA JÚNIOR; FILHO, 2018), o trabalho e esforço coletivo (PAIVA JÚNIOR, 2004; SOUSA, 2010; SOUSA; PAIVA JÚNIOR; LIRA, 2010), a cooperação, bem como o compartilhamento de informações e conhecimentos entre os atores envolvidos (NASCIMENTO, 2018).

Ante o exposto, a concepção de ação empreendedora pública neste trabalho pode ser compreendida pelo esquema teórico apresentado na Figura 1, o qual tem como principal objetivo ampliar as possibilidades de análise no que diz respeito à ocorrência da mesma. 
Figura 1 - Esquema teórico para análise da ocorrência da ação empreendedora no setor público.

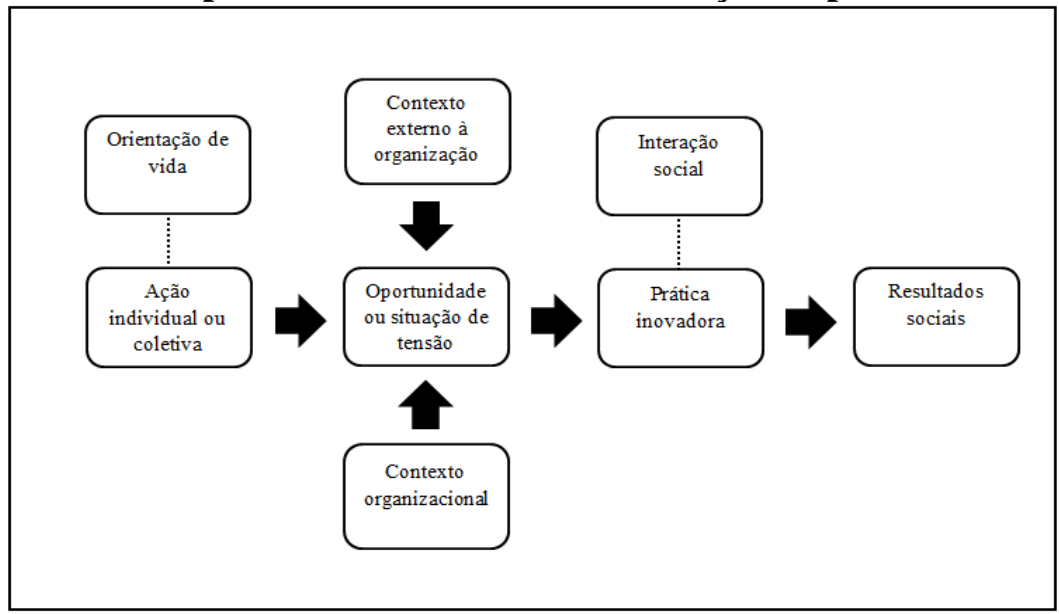

Fonte: Elaborado pelos autores (2019).

Inicialmente, no setor público, a ação empreendedora pode ocorrer a partir de uma ação individual ou coletiva, que pode vir de diferentes níveis hierárquicos da organização ou de pessoas que não fazem parte da estrutura organizacional pública, ou seja, da sociedade civil (BORGES, 2018), após reconhecerem, no contexto organizacional em que estão inseridos ou no contexto externo à organização, que existe uma oportunidade para ser aproveitada (PAIVA JÚNIOR 2004; SOUSA; PAIVA JÚNIOR; LIRA, 2010) ou uma situação de tensão (SPEDALE; WATSON, 2014; NASCIMENTO, 2018) que precisa ser modificada, para que, em ambos os casos, sejam gerados benefícios coletivos (PAIVA JÚNIOR 2004; SOUSA; PAIVA JÚNIOR; LIRA, 2010; XAVIER FILHO et al., 2014).

Ao tomarem iniciativas, os atores empreendedores baseiam-se tanto em sua orientação de vida (WATSON, 2013; SPEDALE; WATSON, 2014; NASCIMENTO, 2018) como nas condições do contexto organizacional e externo (WELTER, 2011). Isso significa que as ações, sejam coletivas ou individuais, que levam ao desenvolvimento de uma ação empreendedora no setor público, não dependem apenas das condições oferecidas pelo contexto organizacional e externo, mas também da história pessoal, das experiências de vida, dos valores éticos e, ainda, dos hábitos positivos dos indivíduos envolvidos na ação (NASCIMENTO, 2018).

A orientação de vida dos indivíduos também influencia no reconhecimento ou identificação de oportunidades, haja vista que estas são retratadas pelos indivíduos como um fenômeno singular e podem ser criadas a partir da interpretação dos mesmos (SARASON; DEAN; DILLARD, 2006).

Cabe detalhar que os atores que estão de fora da estrutura organizacional pública podem se alinhar com o setor público, por razões de interesse (mútuo), a fim de gerar resultados positivos para a sociedade (BORGES, 2018). Nesse sentido, corroborando com o entendimento de Borges e Cappelle (2017), seria possível afirmar que a sociedade civil e o mercado podem participar de uma mesma ação empreendedora pública.

No esquema teórico, a ação, que resulta do reconhecimento de uma oportunidade ou da identificação de uma situação-problema (tensão) no contexto organizacional em que os atores empreendedores estão inseridos ou no contexto externo à organização da qual fazem parte, pode transformar-se em uma prática inovadora (PAIVA JÚNIOR, 2004; SOUSA, 2010; 
SOUSA; PAIVA JÚNIOR; LIRA, 2010; SILVA; VALADARES; ANDRADE, 2016) assumindo diversas formas, como a formulação e implementação de uma política pública (SILVA; VALADARES; ANDRADE, 2016), a criação de novos produtos e serviços ou de um novo empreendimento, a reestruturação de determinado processo, a utilização de métodos de trabalho criativos ou, ainda, a introdução de mudanças administrativas (GOMES; LIMA; CAPPELLE, 2013; NASCIMENTO, 2018), com a principal finalidade de produzir resultados sociais e coletivos no contexto em que foi desenvolvida. Os resultados gerados também podem ser estendidos a outros contextos, modificando, assim, a realidade existente de forma mais abrangente (PAIVA JÚNIOR, 2004; SOUSA, 2010; SOUSA; PAIVA JÚNIOR; LIRA, 2010; GROOT; DANKBAAR; 2014; XAVIER FILHO et al., 2014; SILVA; VALADARES; ANDRADE, 2016).

Vale explicar também que o trabalho e o esforço coletivo (PAIVA JÚNIOR, 2004; SOUSA, 2010; SOUSA; PAIVA JÚNIOR; LIRA, 2010), proporcionados por meio da interação social dos diferentes atores envolvidos na ação empreendedora púbica, pode facilitar e favorecer o desenvolvimento de práticas inovadoras, pois acredita-se que nessa condição normalmente haverá, além da comunicação (GOMES; PAIVA JÚNIOR; FILHO, 2018), o compartilhamento de experiências, informações e conhecimentos entre os participantes (NASCIMENTO, 2018), bem como a criação de uma relação de cooperação e confiança entre os mesmos (GOMES; PAIVA JÚNIOR; FILHO, 2018; NASCIMENTO, 2018).

Embora a ação individual ou coletiva represente o início da ocorrência de uma ação empreendedora pública, observa-se que ela é movida pela interação entre os participantes, os quais podem estar em diferentes níveis hierárquicos da própria organização pública ou fora desta, em outros contextos (ROSSETTO, 1999; COLAUTO; MECCA; LEZANA, 2007; BURKE et al., 2009; BORGES, 2018; NASCIMENTO, 2018).

Nesse sentido, faz-se necessário verificar, empiricamente, a ocorrência da ação empreendedora no setor público, conforme se propõe neste trabalho, cuja estratégia metodológica será detalhada na sequência.

\section{$3 \quad$ Metodologia}

O estudo possui uma abordagem qualitativa e descritiva. Quanto aos procedimentos, pode ser classificado como estudo de caso observacional.

O lócus da pesquisa é o setor de "Pós-compra" de uma UPSMG. Já o objeto de estudo é o processo de criação e implementação do referido setor, criado no final de 2015. Atualmente, o setor é composto por seis colaboradores e está dividido por funções de Secretaria e de Processo Administrativo Sancionatório (PAS), porém, inter-relacionadas.

$\mathrm{Na}$ coleta de informações, foram empregadas três técnicas: observação participante, entrevista semiestruturada e pesquisa documental. Em relação à observação participante, houve a participação nas reuniões destinadas a discutir a estrutura, atribuições, funcionamento e implementação do setor. Observou-se quem eram os participantes, suas ações e os assuntos em pauta. Logo após o término das reuniões, as informações relevantes eram registradas em um caderno de campo e, posteriormente, utilizadas para descrever os participantes e suas ações para estruturar e implementar o setor de "Pós-compra". Participou-se de sete reuniões, com diferentes setores, para tratar de assuntos relacionados à criação do setor. 
A entrevista semiestruturada foi a segunda técnica utilizada. Os entrevistados foram selecionados por meio da amostragem por bola de neve. Nessa técnica, selecionam-se informantes-chave, os quais, por sua vez, indicam outros indivíduos para serem entrevistados. Esse processo se repete até o ponto em que as pessoas indicadas deixam de trazer novas informações para a pesquisa (VINUTO, 2016). Foram entrevistados oito envolvidos, os quais serão tratados por E1, E2, E3, E4, E5, E6, E7 e E8. Utilizou-se um roteiro semiestruturado para conduzir as entrevistas. A primeira foi realizada com o informante-chave, denominado E1, pois, na qualidade de Diretor, além de ser o responsável geral pelo setor de "Pós-compra", é um dos atores que acompanhou todo o processo de criação e implementação do mesmo. O entrevistado "semente" indicou o E2, que por sua vez, indicou o E3, e assim sucessivamente.

A terceira técnica utilizada foi a pesquisa documental. Sá-Silva, Almeida e Guindani (2009) explicam que, na pesquisa documental, o pesquisador utiliza de materiais que ainda não foram objeto de análise, ou seja, recorre a fontes primárias. Foram utilizados dez documentos diferentes, tratados de Doc. 1 até Doc. 10, que envolvem resolução, manual de procedimentos, portaria, fluxograma de atividades e relatórios de gestão de 2013 a 2018.

Os dados obtidos foram analisados segundo a técnica da análise temática, seguindo a sequência de fases proposta por Braun e Clarke (2006): Fase 1 - Familiarização com os dados: envolve a leitura e releitura dos dados para facilitar a identificação de temas; Fase 2 Geração de códigos iniciais: criou-se um código específico para cada fonte de dados utilizada; Fase 3 - Busca de temas: classificação e agrupamento dos dados codificados em temas potenciais; Fase 4 - Revisão dos temas: revisão e refinamento dos temas potenciais; Fase 5 - Definição e nomeação das categorias de análise: foram definidas as categorias de análise que integram o modelo teórico proposto: ação individual ou coletiva, orientação de vida, oportunidade, contexto organizacional, contexto externo à organização, prática inovadora, interação social e resultados sociais; Fase 6 - Produção do relatório: análise final realizada por meio da triangulação dos dados, a fim de responder o problema de pesquisa.

\section{O Processo de Criação e Implementação do Setor de "Pós-compra"}

Até meados de 2016, a Universidade pesquisada tinha muitos problemas em gerenciar o cumprimento das obrigações contratuais e legais por parte dos licitantes e contratadas. Apesar de todo o esforço para realizar a compra de materiais e contratar os serviços demandados pela comunidade universitária, muitas vezes a instituição não era atendida pelos fornecedores.

A Universidade conseguia aquele recurso e depois no final das contas, não conseguia executar por conta de fornecedor que não entrega né (...) (E2)

A Universidade tinha muitos problemas de licitantes que não entregavam ou entregavam produto fora da especificação. (E8)

Na prática, as empresas recebiam os pedidos de fornecimento de materiais ou prestação de serviços, porém, acabavam não cumprindo a obrigação de entregar os produtos ou realizar os serviços. Ademais, era comum o fato de muitos fornecedores entregarem os materiais fora do prazo previsto ou diferente da especificação exigida. Todavia, esses problemas de não atendimento ou atendimento parcial por parte das empresas impactavam diretamente na qualidade dos serviços oferecidos pela Universidade, uma vez que a manutenção do trabalho administrativo e infraestrutura operacional, assim como as atividades de ensino, pesquisa e 
extensão realizadas pela instituição demandam um volume significativo de materiais, equipamentos, prestação de diferentes serviços e realização de obras.

Contudo, a Universidade, por falta de condições, como número reduzido de servidores, não conseguia apurar, de maneira eficiente, os casos em que os fornecedores deixavam de cumprir alguma obrigação contratual. Assim, a instituição alimentava uma espécie de "sensação de impunidade" junto às empresas e não conseguia resolver essa problemática.

(...) a gente tinha muita dificuldade, tinha muitos problemas nesse sentido mesmo de estruturar, faltava servidores, entendeu? (E2)

(...) por anos a Universidade, por questões de recursos humanos mesmo, por falta de servidores, não conseguiu estruturar esse núcleo pra dar de forma efetiva respostas a essas demandas (...) isso criava uma sensação, uma cultura de impunidade. (E4)

Com relação aos casos envolvendo materiais, a Universidade tinha um único servidor lotado na antiga Coordenadoria de Materiais e Patrimônio (Almoxarifado), que fazia contato com as empresas por telefone e solicitava a entrega dos materiais ou a substituição dos produtos entregues com alguma divergência, sem registrar nenhuma informação, ou seja, um procedimento informal. Geralmente, esse procedimento só era realizado quando algum requisitante comunicava ao Almoxarifado que o seu material ainda não havia sido entregue.

Um servidor ficava meio que por conta de cobrar as empresas (...) ele também começou a cobrar empresas atrasadas mais por demanda (...) fazia uma Notificação meio que informal, ligava para a empresa e fazia um controle rústico disso. (E1)

Quanto aos serviços esporádicos e não continuados, o acompanhamento da realização dos mesmos era feito pelo próprio requisitante ou setor responsável. Já os contratos de serviços de obras, contratos de terceirização de mão de obra e demais serviços continuados eram gerenciados e fiscalizados, à época, pela Coordenadoria de Gestão de Contratos vinculada à Pró-Reitoria de Planejamento e Gestão (PROPLAG) da instituição.

Contratos menores, prestação de serviços esporádicos (...) o setor que contratou, que pediu o serviço, via se tava tudo bem e às vezes reclamava ou não (...) (E8)

(...) terceirização de mão de obra ou algum serviço maior (...) acabavam indo lá pra gestão de contratos (...) toda essa questão de contratos grandes e de obras, quem cuidava do "Pós-compra" era o setor de Coordenadoria de Gestão de Contratos (E8)

No que diz respeito à condução dos Processos Administrativos Sancionatórios (PAS) instaurados pela Universidade para apurar o descumprimento de obrigações contratuais e legais, anteriormente, os processos relacionados a fornecimento de materiais e realização de serviços não continuados eram conduzidos por Comissões temporárias, normalmente presididas por um servidor da Diretoria de Gestão de Materiais (DGM). Igualmente, os PAS relacionados a contratos de serviços de obras eram conduzidos por Comissões temporárias e esparsas, isto é, compostas por servidores de diferentes setores.

Eram nomeadas Comissões pra cada problema e essas Comissões eram esparsas né (...) cada um de um local e elas ficavam muito espalhadas (...) (E1) 
Os diferentes casos de descumprimento de obrigações contratuais e legais por parte dos licitantes e contratadas causavam muitos prejuízos para a Universidade. Além da perda de recursos orçamentários, influenciavam na qualidade dos serviços oferecidos à sociedade, comprometiam a execução do orçamento, aumentavam o quantitativo de Empenhos em aberto e de valores inscritos em Restos a Pagar, geravam retrabalho e custos com mão de obra.

Muitas das vezes as empresas não entregavam e como o Empenho é inscrito em Restos a Pagar, a gente perdia esse recurso porque não tinha como empenhar novamente esse recurso. (E1)

(...) virava em Restos a Pagar, não tinha como empenhar pra outro ano e perdia aquele orçamento. (E8)

(...) retrabalho. Isso daí é quase que dinheiro no lixo, porque uma pessoa da DGM tendo que licitar de novo a mesma coisa, todo o processo licitatório (...) (E8)

Como se observa, as práticas de trabalho relacionadas à etapa final do processo de compras e contratação da Universidade não eram efetivas. Não obstante, servidores de diferentes setores, ao perceberem que as práticas da instituição precisavam ser alteradas, começaram a se mobilizar para corrigir as falhas e sanar os problemas existentes. Assim, diante desse contexto marcado pela falta de eficiência, especialmente na realização das cobranças e punição dos fornecedores que causavam problemas para a Universidade, é que surgiu, entre os anos de 2014 e 2015, a necessidade de criar o setor de "Pós-compra".

(...) precisava de um pessoal que controlasse isso, que esse pessoal acionasse os fornecedores para que os fornecedores entregassem dentro do prazo e evitar que os Empenhos fossem inscritos em Restos a Pagar. (E1)

A gente já havia detectado que existiam falhas procedimentais (...) tendo em vista várias reclamações que havia pela falta de efetividade na cobrança e na punição dessas empresas. (E4)

Esses problemas de gestão, constatados pelos servidores, foram levados ao conhecimento da alta direção da instituição, porém, apesar do consenso quanto à necessidade de criar o setor, faltavam números para mostrar a real dimensão dos problemas e justificar a criação do mesmo. Diante disso, espontaneamente, dois servidores lotados na PROPLAG elaboraram, à época, um relatório demonstrando o quanto a instituição estava perdendo recursos orçamentários e apresentaram para a alta direção que, ao tomar conhecimento, ficou convencida da necessidade, apoiou a ideia e solicitou que o setor fosse criado.

(...) só com a questão dessa problemática do Restos a Pagar é que, de fato, a gestão, a alta direção comprou a ideia. (E7)

(...) a gente não tinha números palpáveis (...) o E5 e E7 fizeram o levantamento, realmente o quantitativo de valores, de Empenhos que a gente tava perdendo por causa desses cancelamentos e isso foi um argumento suficiente pra convencer. (E8)

Além disso, outros dois servidores da antiga Coordenadoria de Materiais e Patrimônio visitaram uma Universidade no Estado do Rio Grande do Norte (RN) para entenderem o funcionamento de um novo sistema que a instituição pesquisada estava adotando naquele momento, em 2014. Na ocasião, os servidores constataram que a Universidade visitada 
possuía um setor de "Pós-compra" consolidado e bem estruturado e que este poderia ser utilizado como modelo. Essa visita serviu para reforçar a necessidade de criação do setor.

Lá dentro da Diretoria de Almoxarifado e Patrimônio da Universidade [visitada] eles tinham um setor de "Pós-compra" que fazia essa parte do contato com o fornecedor. Então a gente identificou que isso era uma prática muito interessante né. (E1)

A gente já tinha identificado a necessidade, ai quando a gente foi lá visitar a gente viu que lá eles tinham essa questão estruturada, então melhorou a discussão (...) (E2)

Durante a participação da primeira reunião realizada para discutir as atribuições, escopo de atuação e recursos necessários para o funcionamento do setor, observou-se que a PróReitora de Planejamento e Gestão, à época, expôs sua preocupação com relação ao fato de que a Universidade não estava eficiente na realização dos trabalhos de punição das empresas.

Contudo, somente no final de 2015 é que o setor de "Pós-compra" começou a funcionar com três colaboradores, os quais foram responsáveis pela criação dos primeiros procedimentos e rotinas de trabalho que serviram de referência para a posterior elaboração do Manual de procedimentos do setor (Doc. 2). No entanto, alguns trabalhos desenvolvidos anteriormente por outros servidores foram aproveitados e adaptados, como é o caso do fluxograma de tramitação dos Processos Administrativos Sancionatórios no âmbito da instituição elaborado por um servidor da DGM.

Os servidores que formaram a primeira equipe do "Pós-compra" também consultaram outras IFES, a fim de identificar se possuíam um setor semelhante e quais atividades o setor realizava, fato que foi exposto e observado durante a participação da primeira reunião. Esses estudos serviram como parâmetro para a criação dos procedimentos e estruturação do setor na Universidade pesquisada. Além da cooperação dessas IFES, outros servidores e setores da instituição contribuíram, de maneira recorrente, para o aperfeiçoamento das atividades e serviços prestados pelo setor de "Pós-compra".

O setor de "Pós-compra" está diretamente subordinado à DMP, a qual, por sua vez, está subordinada à PROPLAG da instituição. Em outubro de 2017, quando o Regimento Interno da DMP (Doc. 1) foi aprovado, o setor de "Pós-compra" passou a ser denominado Coordenadoria de Pós-Aquisição de Materiais e Serviços (CPAM). Atualmente, o setor é composto por seis colaboradores. Com relação à estrutura interna, o setor está dividido em duas áreas principais: área de Secretaria e área de Processo Administrativo Sancionatório (PAS). No entanto, ambas as áreas trabalham de forma integrada e inter-relacionada.

Dentro da área de Secretaria, são realizadas as seguintes atividades que constam do Manual de procedimentos do setor (Doc. 2) e do Fluxograma de atividades e processos (Doc. 4) utilizados neste trabalho: i) envio das Notas de Empenho aos fornecedores; ii) monitoramento e controle do prazo de entrega das mercadorias; iii) notificação de empresas por atraso na entrega dos materiais; iv) análise dos pedidos de prorrogação do prazo de entrega; v) análise dos pedidos de substituição de marca/modelo; vi) emissão de Atestados de Capacidade Técnica; vii) atendimento ao público interno e externo da instituição; e outras.

Já no âmbito da área de PAS, existe uma Comissão Processante Permanente, instituída por Portaria da PROPLAG (Doc. 3), composta por três servidores, que recebe as comunicações de irregularidades relacionadas à execução de contratos de obras, realização de serviços e fornecimento de materiais e verifica se existem indícios de autoria e materialidade 
suficientes para a recomendação de instauração de PAS. Essa Comissão também conduz os PAS instaurados pela Autoridade Competente, a fim de apurar o descumprimento de obrigações contratuais e legais por parte dos licitantes e empresas contratadas.

\section{Discussão e Implicações das Ações Empreendedoras: o Caso do Setor de "Pós-compra"}

A criação do setor de "Pós-compra" na Universidade pesquisada ocorreu a partir de uma ação coletiva, vinda de servidores de diferentes setores e níveis hierárquicos da instituição (BORGES, 2018) após reconhecerem, no contexto organizacional em que estão inseridos, uma situação de tensão (SPEDALE; WATSON, 2014; NASCIMENTO, 2018) que precisava ser modificada. Esta tensão institucional era caracterizada pela falta de efetividade nas práticas de monitoramento e controle do cumprimento das obrigações contratuais e legais por parte dos fornecedores, além da ineficiência em sancionar as empresas pelo descumprimento das referidas obrigações. Ao mesmo tempo, o setor de "Pós-compra" foi uma oportunidade (SARASON; DEAN; DILLARD, 2006) que os servidores identificaram para que a instituição pudesse acabar com a "sensação de impunidade" por parte dos seus fornecedores.

Essa situação era fonte de muitos problemas para a Universidade, pois causava perda de recursos orçamentários, comprometia a execução do orçamento, aumentava o quantitativo de Empenhos em aberto e de valores inscritos em Restos a Pagar, gerava retrabalhos e gastos com mão de obra, além de prejudicar as atividades-meio e fim realizadas pela instituição. Alguns servidores, entretanto, começaram a perceber as tensões ao identificarem que as práticas da instituição precisavam ser alteradas (SPEDALE; WATSON, 2014). Assim, incomodados com essa tensão no contexto organizacional (THORNTON; OCASIO, 1999; SPEDALE; WATSON, 2014), começaram a agir de um modo diferente (WATSON, 2013; SPEDALE; WATSON, 2014) e se mobilizaram para solucioná-la.

Não obstante, além do contexto organizacional, a orientação de vida (WATSON, 2013; SPEDALE; WATSON, 2014) também influenciou nas atitudes desses servidores, visto que cada servidor atribuiu um significado diferente à sua participação dentro do processo de criação e implementação do setor, quais sejam: realização profissional, vontade de fazer diferente, gosto pelo trabalho e desejo de ser bem-visto pela comunidade acadêmica.

Do mesmo modo, a história pessoal, as vivências (participação em eventos e realização de cursos), as experiências adquiridas no trabalho, os valores éticos (preocupação em querer atender aos princípios da Administração Pública) e o emprego de determinados hábitos positivos influenciaram nas ações realizadas por esses servidores (NASCIMENTO, 2018). Ademais, o contexto externo à Universidade (WELTER, 2011), especialmente por meio das estruturas legais e de outras organizações, influenciou no desenvolvimento da ação que levou à criação e implementação do setor (ROSSETTO, 1999; COLAUTO; MECCA; LEZANA, 2007; BURKE et al., 2009). Embora as estruturas legais tenham influenciado na ocorrência dessa ação empreendedora, a criação do setor não foi uma imposição legal, mas sim uma ação da Universidade para, entre outros motivos, atender a legislação de forma mais eficiente. Outras organizações, por sua vez, serviram como parâmetro para a instituição estruturar e definir o nome do setor.

A ação coletiva de criação do setor de "Pós-compra", resultante do reconhecimento de uma situação-problema (tensão) no contexto da Universidade, transformou-se em uma prática inovadora (PAIVA JÚNIOR, 2004; SOUSA, 2010; SOUSA; PAIVA JÚNIOR; LIRA, 2010; 
SILVA; VALADARES; ANDRADE, 2016), assumindo, neste caso, a forma de uma mudança administrativa promovida pela instituição, na medida em que houve, notadamente, a melhoria da gestão e a reestruturação de um processo administrativo que era ineficiente (GOMES; LIMA; CAPPELLE, 2013; NASCIMENTO, 2018).

Os diferentes resultados sociais proporcionados pelo setor de "Pós-compra" se manifestaram por meio da geração de benefícios quantitativos e qualitativos para toda a comunidade universitária e do atendimento ao interesse público (PAIVA JÚNIOR, 2004; SOUSA, 2010; XAVIER FILHO et al., 2014). Os benefícios quantitativos foram a redução de valores empenhados inscritos em Restos a Pagar, melhoria da execução orçamentária e da gestão de recursos e, ainda, a melhoria dos índices contábeis da instituição.

Quanto à redução de valores inscritos em Restos a Pagar, antes de o setor de "Póscompra" ser criado, o percentual médio de despesas com materiais de consumo e equipamentos ${ }^{1}$ inscritas em Restos a Pagar nos anos de 2012, 2013 e 2014 foi de $61 \%$. Isso significa que, nos três anos anteriores à criação do setor de "Pós-compra", em média, $61 \%$ do total das despesas empenhadas pela instituição para a aquisição de materiais e equipamentos foram inscritos em Restos a Pagar. Não obstante, nos três anos seguintes à criação do setor, ou seja, nos anos de 2016, 2017 e 2018, esse percentual médio caiu para 49\%, conforme se extrai das informações constantes dos Relatórios de Gestão de 2013, 2014, 2015, 2016, 2017 e 2018 da Universidade pesquisada, respectivamente, Docs. 5, 6, 7, 8, 9 e 10 utilizados.

Já com relação aos benefícios sociais qualitativos (PAIVA JÚNIOR, 2004; SOUSA, 2010; XAVIER FILHO et al., 2014) cita-se, incialmente, a mudança da visão que muitos fornecedores tinham da Universidade quanto à falta de eficiência nas cobranças e punições, o que diminuiu o número de infrações cometidas pelas empresas. Em segundo lugar, esta ação empreendedora beneficiou todos os membros da comunidade universitária ao oferecer mais suporte, fazendo as pessoas se sentirem mais assistidas com o trabalho realizado pelo setor.

Outro resultado social gerado com a criação do setor está voltado ao atendimento do interesse público da comunidade acadêmica (PAIVA JÚNIOR, 2004; SOUSA, 2010; XAVIER FILHO et al., 2014), pois com o trabalho desenvolvido pelo setor, as necessidades de docentes, servidores técnico-administrativos e alunos da Universidade passaram a ser atendidas de forma mais efetiva. Na prática, muitas empresas começaram a entregar os materiais - demandados pelos docentes para a realização de pesquisas, experimentos, etc. e pelos técnico-administrativos para o desempenho de suas funções no dia a dia - dentro do prazo previsto e com a qualidade exigida, o que impacta, de maneira positiva, na qualidade do ensino oferecido, nas pesquisas desenvolvidas e na extensão promovida pela Universidade.

Ademais, o fato de o setor de "Pós-compra" ter proporcionado uma melhoria na gestão da Universidade, tornando-a mais eficiente, em consonância com os princípios da economicidade, legalidade e eficiência da Administração Pública, demonstra que esta ação empreendedora buscou atender ao interesse público (PAIVA JÚNIOR, 2004; SOUSA, 2010; XAVIER FILHO et al., 2014).

Ainda, os resultados sociais gerados com a criação do setor de "Pós-compra" podem ser estendidos a outros contextos (PAIVA JÚNIOR, 2004; SOUSA, 2010; SOUSA; PAIVA

${ }^{1}$ Foram consideradas apenas as despesas com materiais de consumo e equipamentos, visto que o escopo de atuação direta do setor de "Pós-compra" está circunscrito à aquisição de materiais e equipamentos. Dessa forma, as despesas empenhadas pela instituição com serviços e obras não foram consideradas nos percentuais apresentados. 
JÚNIOR; LIRA, 2010; GROOT; DANKBAAR; 2014; XAVIER FILHO et al., 2014; SILVA; VALADARES; ANDRADE, 2016). Isso acontece porque quando a Universidade aplica, por exemplo, uma sanção que restringe o direito de uma empresa participar de licitações ou contratar com toda a Administração Pública, ela evita que esta empresa, que cometeu alguma infração mais grave, participe de licitações promovidas por outros órgãos públicos. Este exemplo demonstra que o trabalho realizado pelo setor de "Pós-compra" está interrelacionado com todo o sistema de licitação pública. A partir dessa perspectiva, tem-se, novamente, que a criação do setor está relacionada ao atendimento do interesse público (PAIVA JÚNIOR, 2004; SOUSA, 2010; XAVIER FILHO et al., 2014).

A interação social entre os diferentes servidores e setores da Universidade influenciou, de maneira positiva, nas ações desenvolvidas ao longo do processo de criação e implementação do setor de "Pós-compra". Ela ocorria de diferentes maneiras, a começar pela constante comunicação (GOMES; PAIVA JÚNIOR; FILHO, 2018) que havia entre esses servidores e setores, por meio de reuniões e conversas no dia a dia. A cooperação e o compartilhamento de informações e conhecimentos entre esses servidores e setores também era outra forma de interação. Ademais, houve a cooperação de outros órgãos públicos que compartilharam informações e boas práticas.

Além do mais, o trabalho e esforço coletivo dos diferentes servidores e setores da Universidade contribuiu para a resolução das tensões institucionais que existiam (WATSON, 2013; SPEDALE; WATSON, 2014; NASCIMENTO, 2018). Isso demonstra que a criação do setor de "Pós-compra" e os resultados gerados refletem um esforço conjunto (PAIVA JÚNIOR, 2004; SOUSA, 2010; SOUSA; PAIVA JÚNIOR; LIRA, 2010) que mobilizou diferentes pessoas e setores, além de envolver outras organizações públicas.

Embora a ação coletiva tenha representado o início da ocorrência desta ação empreendedora pública que levou à criação do setor, ela foi movida pela interação entre os servidores (atores) lotados em diferentes setores administrativos e níveis hierárquicos da instituição (BORGES, 2018) - DMP, Almoxarifado, DCONT, DGM e PROPLAG - e também pela interação com atores de outros contextos, ou seja, pessoas que estão em outras organizações (ROSSETTO, 1999; COLAUTO; MECCA; LEZANA, 2007; BURKE et al., 2009; BORGES, 2018; NASCIMENTO, 2018).

Constatou-se que a criação e implementação do setor de "Pós-compra" foram influenciadas por diferentes fatores: contexto organizacional, incluindo as lógicas e tensões institucionais verificadas, contexto externo à organização, orientação de vida dos indivíduos e interação social dos servidores e setores envolvidos. Ademais, esta ação empreendedora pública foi identificada pelos diferentes resultados positivos gerados no contexto da Universidade (GROOT; DANKBAAR; 2014; SILVA; VALADARES; ANDRADE, 2016).

Diversas características da ação empreendedora pública trazidas pela literatura podem ser encontradas na criação e implementação do setor de "Pós-compra". A primeira está relacionada ao fato de ter sido uma ação coletiva oriunda de servidores de diferentes setores e níveis hierárquicos da organização, conforme apontado por Borges (2018). Em segundo lugar, em consonância com o entendimento de Nascimento (2018), foi uma ação que surgiu do diálogo e do compartilhamento de informações e conhecimentos entre diferentes pessoas, departamentos e outros órgãos públicos na busca pela resolução de tensões. 
O setor de "Pós-compra" também gerou resultados positivos no contexto em que foi criado, os quais foram reconhecidos pelos membros da própria comunidade universitária, aspecto trazido por Groot e Dankbaar (2014) e Silva, Valadares e Andrade (2016). Além disso, foi possível identificar a presença de valores éticos nesta ação, os quais, conforme explicado por Sousa, Paiva Júnior e Lira (2010), orientaram a boa conduta dos envolvidos.

Em acréscimo, a criação do setor de "Pós-compra" foi uma prática inovadora que rompeu com determinadas práticas organizacionais que não eram eficientes, conforme explicado por Paiva Júnior (2004), Sousa (2010) e Sousa, Paiva Júnior e Lira (2010).

Derradeiramente, de acordo com o entendimento de Paiva Júnior (2004) e Sousa (2010), foi uma ação que procurou satisfazer os interesses da coletividade, o que pode ser constatado por meio dos resultados sociais proporcionados com a criação do setor, dentre eles, a geração de benefícios sociais, a satisfação das necessidades do cidadão (docentes, servidores técnicoadministrativos e discentes) e o atendimento do interesse público, os quais são citados por Paiva Júnior (2004), Sousa (2010) e Xavier Filho et al. (2014).

\section{Considerações finais}

O objetivo deste artigo foi descrever o processo de criação e implementação do setor de "Pós-compra" em uma Universidade pública do sul de Minas Gerais e analisar se essa ação pode ser considerada empreendedora. Sendo assim, foi necessário trazer para o centro da discussão a perspectiva da ação empreendedora no contexto do setor público, com foco em demonstrar seus desdobramentos na área de compras e contratações públicas.

Com base na discussão realizada neste trabalho, tem-se que, no setor público, a ação empreendedora procura satisfazer os interesses da coletividade, ou seja, é uma ação voltada para servir ao cidadão e gerar benefícios sociais.

Verificou-se que o processo de criação do setor de "Pós-compra" na Universidade pesquisada iniciou-se no final do ano de 2015 em um contexto marcado pela falta de eficiência no acompanhamento e monitoramento das obrigações contratuais e legais por parte dos licitantes e empresas contratadas pela instituição.

Diferentes características da ação empreendedora no setor público, trazidas pela literatura, foram identificadas ao longo do processo de criação e implementação do setor de "Pós-compra". Desse modo, pelas características apresentadas, a criação do setor de "Póscompra" pode ser compreendida como uma ação empreendedora pública desenvolvida no contexto da Universidade pesquisada.

Argumenta-se que o esquema teórico proposto pode ser empregado em novos estudos e pesquisas empíricas com o intuito de compreender a ocorrência da ação empreendedora no setor público. Não obstante, para futuras agendas de pesquisa, sugere-se que o esquema proposto seja utilizado em diferentes órgãos públicos (além de IFES) e esferas de governo cuja realidade seja distinta da que foi estudada.

\section{$7 \quad$ Referências}

ABREU, E. R. O processo de sanção administrativa como instrumento de preservação do interesse público na relação entre a administração pública e as empresas licitantes: uma análise prática da aplicação da Lei $\mathrm{n}^{\circ}$. 8.666/1993 e da Lei $\mathrm{n}^{\circ}$. 10.520/2002. 2015. 58 p. Monografia (Bacharel em Direito) - Faculdade de Direito, Universidade de Brasília, Brasília, 2015. 
ASSIS, S. A. F. Modernização da burocracia das compras públicas: sistema de registro de preços em uma Instituição Federal de Ensino Superior. 2015. Dissertação (mestrado profissional) Universidade Federal de Lavras, Lavras, 2015.

BIAZZI, M. R.; MUSCAT, A. R. N.; BIAZZI, J. L. Modelo de aperfeiçoamento de processos em instituições públicas de ensino superior. Gestão \& Produção, v. 18, n. 4, p. 869-880, 2011.

BORGES, D. A. H. Muito mais que uma política: ações empreendedoras no esporte de Lavras/MG. 2018. 101 p. Dissertação (Mestrado em Administração) - Universidade Federal de Lavras, Lavras, 2018.

BORGES. D. A. H.; CAPPELLE. M. C. A. Ação empreendedora: uma estratégia para o planejamento público brasileiro. In: I SIEGEP, 2017, Lavras. Anais... Lavras, p. 8, 2017.

BOSZCZOWSKI, A. K.; TEIXEIRA, R. M. O empreendedorismo sustentável e o processo empreendedor: em busca de oportunidades de novos negócios como solução para problemas sociais e ambientais. Revista Economia \& Gestão, v. 12, n. 29, p. 109-127, 2012.

BRASIL. Portal de Compras do Governo Federal. Painel de Compras, 2019. Disponível em: $<$ http://paineldecompras.planejamento.gov.br/QvAJAXZfc/opendoc.htm?document=paineldecompras. qvw\&lang=en-US\&host=QVS\%40srvbsaiasprd04\&anonymous=true >. Acesso em: 11 jan. 2019.

BRASIL. Ministério da Educação. Portal UFLA, 2018. Disponível em:

$<$ https://ufla.br/noticias/institucional/12481-ufla-e-o-orgao-federal-menos-vulneravel-a-fraude-ecorrupcao-em-minas-gerais>. Acesso em: 06 jan. 2019.

BRAUN, V.; CLARKE, V. Using thematic analysis in psychology. Qualitative Research in Psychology, v. 3, n. 2, p. 77-101, 2006.

BURKE, N. J. et al. Theorizing social context: rethinking behavioral theory. Health Education \& Behavior, v. 36, n. 5, p. 55-70, 2009.

COLAUTO, R. D.; MECCA, M. S.; LEZANA, A. G. R. Gestão governamental: análise SWOT em estudo situacional de um município de Minas Gerais. In: XIV Congresso Brasileiro de Custos, 2007, João Pessoa. Anais... João Pessoa, 2007.

GOMES, A. F.; LIMA, J. B.; CAPPELLE, M. C. A. Do empreendedorismo à noção de ações empreendedoras: reflexões teóricas. Revista Alcance (Online), v. 20, n. 2, p. 203-220, abr./jun. 2013. GOMES, A. F. Ação empreendedora e relações de gênero: um estudo multicasos na cidade de Vitória da Conquista, Bahia. 2010. 440 p. Tese (Doutorado em Administração) - Universidade Federal de Lavras, Lavras, MG, 2010.

GOMES, J. D. M.; PAIVA JÚNIOR, F.; FILHO, J. L. J. X. A ação empreendedora de produtores de jogos independentes inspirada no effectuation. In: X EGEPE, 2018, São Paulo. Anais... São Paulo, p. $1-15,2018$.

GROOT, A.; DANKBAAR, B. Does Social Innovation Require Social

Entrepreneurship?. Technology Innovation Management Review, v. 4, n. 12, p.17-26, 2014.

GUIMARÃES, J. C. Os elementos de inteligência empreendedora como promotores de eficiência organizacional: um fenômeno na academia. Perspectivas em Gestão \& Conhecimento, v. 4, n. 1, p. 38-56, jan./jun. 2014.

KLEIN, P. G. Opportunity discovery, entrepreneurial action, and economic organization. Strategic Entrepreneurship Journal, v. 2, n. 3, p. 175-190, 2008.

LIMA, J. B. Ações empreendedoras e práticas da pesquisa em empreendedorismo. In: GIMENEZ, F.; FERREIRA, J. M.; RAMOS, S. C. (Org.). Empreendedorismo e estratégia de empresas de pequeno porte - 3Es2Ps. Curitiba: Champagnat, 2010. p. 25-40.

MARQUES, T. W. R. O empreendedorismo universitário pela dinâmica da ação empreendedora no Centro de Informática da Universidade Federal de Pernambuco. 2016. 120 p. Dissertação (Mestrado em Administração) - Universidade Federal de Pernambuco, Recife, 2016. 
NASCIMENTO, P. O. A ação empreendedora na gestão pública escolar. 2018. 127 p. Dissertação (Mestrado em Administração Pública) - Universidade Federal de Lavras, Lavras, 2018.

PAIVA JÚNIOR, F. G. O empreendedorismo na ação de empreender: uma análise sob o enfoque da fenomenologia social de Alfred Schutz. 2004. 369 p. Tese (Doutorado em Administração) Universidade Federal de Minas Gerais, Belo Horizonte, 2004.

PINHEIRO, P. R. Gerência de pós-compra da Universidade Federal de Juiz de Fora: uma proposta de reestruturação. 2017. 119 p. Dissertação (Mestrado Profissional em Gestão e Avaliação da Educação Pública) - Universidade Federal de Juiz de Fora, Juiz de Fora, 2017.

ROSSETTO, A. M. Estrutura organizacional pública como um entrave à adoção de inovações em tecnologia de informações. In: XXIII ENCONTRO DA ANPAD, 1999, Foz do Iguaçu. Anais... Foz do Iguaçu, 1999.

SARASON, Y.; DEAN, T.; DILLARD, J. F. Entrepreneurship as the nexus of individual and opportunity: a structuration view. Journal of Business Venturing, New York, v. 21, p. 286-305, 2006.

SÁ-SILVA, J. R.; ALMEIDA, C. D.; GUINDANI, J. F. Pesquisa documental: pistas teóricas e metodológicas. Revista brasileira de história \& ciências sociais, v. 1, n. 1, p. 1-15, jul. 2009. SILVA, C. A.; VALADARES, J. L.; ANDRADE, D. M. Ações empreendedoras na gestão pública: análise do programa crédito solidário (PCS) em um município do sul de Minas Gerais. Revista Eletrônica de Ciência Administrativa, Curitiba, v. 15, n. 1, p.55-68, jan./abr. 2016.

SOUSA, J. L. A ação empreendedora em uma instituição fundacional do setor público: o caso da Fundação Joaquim Nabuco. 2010. 170 p. Dissertação (Mestrado) - Universidade Federal de Pernambuco, Recife, 2010.

SOUSA, J. L.; PAIVA JÚNIOR, F. G.; LIRA, Z. B. A abordagem multidimensional do empreendedorismo no setor público: o caso da ação empreendedora da fundação Joaquim Nabuco. Revista Gestão \& Planejamento, v. 11, n. 2, p. 337-354, 2010.

SPEDALE, S.; WATSON, T. J. The emergence of entrepreneurial action: At the crossroads between institutional logics and individual life-orientation. International Small Business Journal, v. 32, n. 7, p. 759-776, 2014.

THORNTON, P. H.; OCASIO, W. Institutional logics and the historical contingency of power in organizations: Executive succession in the higher education publishing industry, 1958-

1990. American jornal of Sociology, v. 105, n. 3, p. 801-843, 1999.

VINUTO, J. A amostragem em bola de neve na pesquisa qualitativa: um debate em aberto. Temáticas, n. 44, 2016.

WATSON, T. J. Entrepreneurship in action: bringing together the individual, organizational and institutional dimensions of entrepreneurial action. Entrepreneurship \& Regional Development, v. 25, n. 5-6, p. 404-422, 2013.

WELTER, F. Contextualizing entrepreneurship-conceptual challenges and ways forward. Entrepreneurship theory and Practice, v. 35, n. 1, p. 165-184, 2011.

XAVIER FILHO, J. L. J. et al. O empreendedorismo social como alicerce do "Programa Empreender Comunidade”. Revista Interdisciplinar de Gestão Social, v. 3, n. 1, p. 59-83, jan./abr., 2014.

ZEN, A. C.; FRACASSO, E. M. Quem é o empreendedor? As implicações de três revoluções tecnológicas na construção do termo empreendedor. RAM, Rev. Adm. Mackenzie (Online), São Paulo, v. 9, n. 8, p. 135-150, 2008. 